\title{
THE EFFECT OF THE ADAPTED PHYSICAL ACTIVITY PROGRAM ON THE PSYCHOMOTOR PERFORMANCE AND THE QUALITY OF LIFE FOR PATIENTS WITH BREAST CANCER
}

Background

The theoretical provisions of the research embraced the idea of Fully Functioning Self Theory that person-centered therapies help a person to realistically assess their opportunities and increase their personal activities as well as target them for rehabilitation and education purposes ( pioneered by C. Rogers (1902-1987). Purpose: to determine the effect of the Adapted Physical Activity Program (APAP) on the psychomotor parameters ( $P P$ ) and the quality of life ( $Q L$ ) in women with breast cancer in the late postoperative period.

Research methods and organization

Research participants were 40 subjects aged $55 \pm 19$ years. The evaluated PP of the subjects were: muscle strength of the hand by a dynamometer, degree of lymphadema by a centimeter strip, pain sensation - by a visual pain scale (VPS), physical fitness tolerance - 6 min walking test; the quality of life - the EORTC QLQ_C30 and BR23 questionnaires.

Egle Kalvaitiene ${ }^{1,2}$, Laimute Samsoniene ${ }^{1}$, Nomeda Vaitiekūniene ${ }^{2}$

Institute of Health Sciences Faculty of Medicine Vilnius University ${ }^{1}$ National Cancer Institute ${ }^{2}$

\section{Results}

The PP of the experimental group improved after the application of the APAP ( $P<0.05)$ : the average shoulder range of motion improved on average - bending by 17 degrees ( $51.5 \%$ ), a retraction by18 degrees ( $56.75 \%$ ), stretching - by 5 degrees (11.5\%); the hand grip strength of the operated arm increased by $1 \mathrm{~kg}$ (2.9\%) on average; $6 \mathrm{~min}$. walking test improved on average by $36 \mathrm{~m}$ ( $84.3 \%$ ); after the application of physical activity, the pain in patients decreased an average by 0.5 points (32.3\%). Physical parameters of the control group did not change ( $p_{>} 0.05$ ). In the experimental group, significant correlations were found between the $Q \mathrm{~L}$ scales and physical parameters $(r=0.40-0.69)$

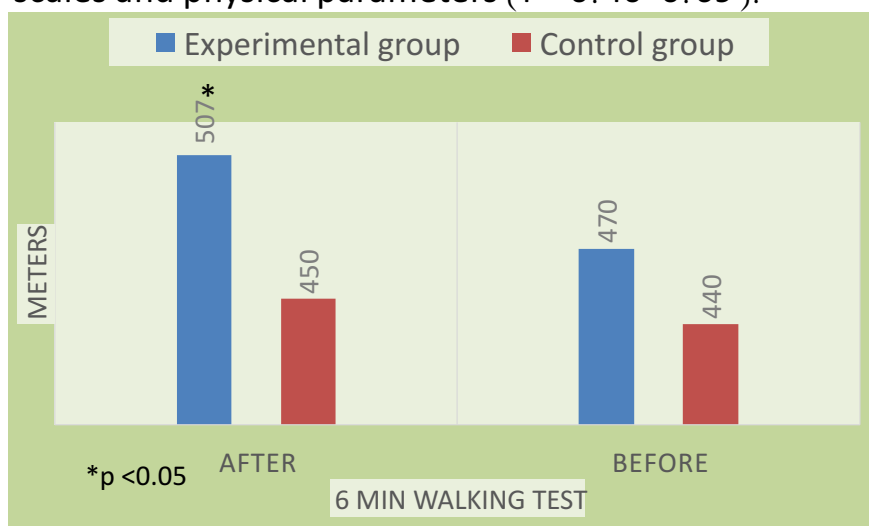

Conlusions

1. The APAP applied during rehabilitation improved PP ( $P$ $\langle 0.05)$ in the experimental group, while the parameters in the control group remained unchanged $(p>0.05$ ); subjectively evaluated pain decreased in the study group $(\boldsymbol{p}<0.05)$.

2. The impact of morbidity on the QL was determined in the following areas: a positive shift in the emotional functioning, body imagination scales in the experimental group, and a negative shift in fatigue, side effects of systemic treatment and response to hair loss scales ( $p<0.05$ ); in the control group there was a positive shift in roles and social functioning scales $(\mathrm{p}<0.05)$

\section{References}

Hagner_Derengowska, M., Kałużny, K., Hagner, W., Kochański, B., Plaskiewicz, A., Borkowska, A. Budzyński, J. (2015). The influence of a ten-week Nordic walking training-rehabilitation program on the level of lipids in blood in overweight and obese postmenopausal women. Journal of Physical Therapy Science, 27, 10 ), 3039-3044.

Fischer, M. J., Krol_Warmerdam, E. M., Ranke, G. M., Vermeulen, H. M., Van der Heijden, J., \& Stick ( 2015 ). Together: A Nordic Walking group intervention for breast cancer survivors. Journal of Psychosocial Oncology, 33(3), 278-96 